\title{
ANALISIS KEBUTUHAN BAHASA INGGRIS UNTUK MEWUJUDKAN DESA WISATA PENDIDIKAN SENI DAN BUDAYA DI DESA PLESUNGAN
}

\author{
Luqman Al Hakim, Sri Handayani, Ria Santika, Nimas Ayu Melati \\ Program Studi Pendidikan Bahasa Inggris \\ Universitas Slamet Riyadi
}

Masuk: Maret 2020

Revisi: Mei 2020

Diterima:Juli 2020

Terbit: Agustus 2020

Keywords:

Plesungan Village, English, Foreign Tourists

Kata kunci:

Desa Plesungan,

Bahasa Inggris,

Wisatawan

Mancanegara

P-ISSN: 2598-2273

E-ISSN: 2598-2281

\begin{abstract}
The development of Plesungan village in terms of tourism, arts and culture has led to an increase in infrastructure, empowerment of human resources, and exploration of natural resources. The tourism sector in the form of a spring spring develops well along with the increase in the number of visitors thereby increasing income for the village spring. In the field of arts and culture, the diversity of art performances, in the form of a festival of spring play, white hermitage, reog, and studio studio are a form of preservation and development of local arts and culture and a form of regeneration for local young people. The improvement of facilities and infrastructure to support tourism, arts and culture in the village of Plesungan is useful for preserving the existence of local potential and increasing local tourist visits and expanding to foreign tourists. Exploration of natural resources to expand the area of tourism is important to develop the potential of villages that lead to the optimal use of natural resources to realize the welfare of the Plesungan village community.

The role of human resources in developing the potential of Plesungan village is inseparable from activities that are creative, innovative, and have promotive value. The use of polite, polite and good values is a promotive activity to increase the number of tourists visiting Plesungan village. Regional language skills and Indonesian language show an attitude of patriotism and preserve local culture, but foreign language skills, especially English are also things that need to be realized to attract foreign tourists visiting. Realizing competent and skilled human resources in English requires concrete steps, including an analysis of English language needs to identify the variety of English needed to support tourism in the village of Plesungan. Positive responses from the public about the English needs of foreign tourists need to be improved in an effort to facilitate their visit.

The results of this dedication are (1) the acquisition of the variety of English that is needed for the Plesungan village tourism business, namely Introducing myself; ask and provide information (asking and giving information); offering products / souvenirs typical of the village (offering local souvenirs), giving advice (giving suggestion); and invite (invitation); (2) Plesungan residents' profiles that $75 \%$ of residents are in the productive age category so that they are expected to develop the potential of tourism and local cultural arts; and (3) optimization of digital-based village promotion through social media is needed both in Indonesian and English.
\end{abstract}

\section{Abstrak}


Perkembangan desa Plesungan dalam hal kepariwisataan, seni, dan budaya mendorong peningkatan sarana prasarana, pemberdayaan sumber daya manusia, dan explorasi sumber daya alam. Bidang kepariwisataan berupa sendang plesungan berkembang dengan baik seiring dengan peningkatan jumlah pengunjung sehingga meningkatkan income bagi desa plesungan. Dalam bidang seni dan budaya, beragamnya pertunjukan seni, berupa festifal sendang plesungan, padepokan lemah putih, reog, dan studio plesungan merupakan bentuk pelestarian dan pengembangan seni dan budaya lokal dan wujud regenerasi bagi generasi muda setempat. Peningkatan sarana dan prasarana penunjang kepariwisataan, seni dan budaya desa Plesungan bermanfaat untuk melestarikan eksistensi potensi lokal dan meningkatkan kunjungan wisatawan lokal dan meluas ke wisatawan mancanegara. Eksplorasi sumber daya alam untuk memperluas area kepariwisataan merupakan hal yang penting untuk mengembangkan potensi desa yang bermuara pada pemanfaatan secara optimal sumber daya alam untuk mewujudkan kesejahteraan masyarakat desa Plesungan.

Peranan sumber daya manusia dalam pengembangan potensi desa Plesungan tidak terlepas dari kegiatan yang bersifat kreatif, inovatif, dan memiliki nilai promotif. Penggunaan bahasa yang santun, sopan, dan menggunakan tata nilai yang baik merupakan aktifitas yang bernilai promotif untuk meningkatkan jumlah wisatawan yang berkunjung di desa Plesungan. Kecakapan berbahasa daerah dan bahasa Indonesia menunjukkan sikap cinta tanah air dan melestarikan budaya lokal, namun ketrampilan berbahasa mancanegara, khususnya bahasa Inggris juga merupakan hal yang perlu diwujudkan untuk menarik kunjungan wisatawan mancanegara. Mewujudkan sumber daya manusia yang cakap dan terampil dalam berbahasa Inggris memerlukan langkah-langkah konkret, diantaranya adalah analisa kebutuhan bahasa Inggris untuk mengidentifikasi ragam bahasa Inggris yang diperlukan untuk menunjang kepariwisataan desa Plesungan. Respon positif dari masyarakat tentang kebutuhan bahasa Inggris wisatawan mancanegara perlu ditingkatkan sebagai upaya memfasilitasi kunjungan mereka.

Hasil pengabdian ini adalah (1) diperolehnya ragam bahasa Inggris yang diperlukan bagi pelaku usaha wisata desa Plesungan, yaitu Pengenalan diri (Introducing myself); bertanya dan memberikan informasi (asking and giving information); menawarkan produk/cinderamata khas desa (offering local souvenirs), memberikan saran (giving suggestion); dan mengundang (invitation); (2) profil warga Plesungan bahwa $75 \%$ warga termasuk kategori usia produktif sehingga diharapkan dapat mengembangkan potensi kepariwisataan dan seni budaya lokal; dan (3) optimalisasi promosi desa berbasis digital melalui media sosial diperlukan baik dalam bentuk bahasa Indonesia maupun bahasa Inggris. 
Potensi Desa Plesungan sebagai desa wisata mulai tampak sejak dibukanya obyek wisata Sendang Plesungan sebagai tempat berkegiatan outbond dan wahana pendidikan pada bulan Desember 2017 yang berperan dalam peningkatan ekonomi, sosial, dan sumber daya manusia. Dari segi ekonomi, warga Plesungan mengalami peningkatan ekonomi sebab dengan pemasukan tiket masuk sebesar Rp. 75.000.000,- setiap bulannya dapat untuk menggaji 18 karyawan (Tribunnews.com). Sedangkan dari segi sosial dan sumber daya manusia, obyek tersebut meningkatkan keterlibatan warga dalam mengenalkan tentang seni, budaya, dan tradisi warga Plesungan, yaitu tradisi sedekah bumi dengan mengarak dan membagikan 1000 tumpeng dari kantor desa Plesungan menuju sendang Plesungan yang merupakan wujud rasa syukur dan mengangkat potensi lokal desa. (https://www.jawapos.com/radarsolo/read/2018/04/19 /66328/ogoh-ogoh-hiasi-sedekahbumi-desa-plesungan)

Plesungan juga memiliki potensi seni berupa Padepokan Lemah Putih yang berperan dalam rangka peningkatan wawasan dan keterlibatan masyarakat dalam pelestarian budaya lokal. Padepokan tersebut memiliki kegiatan rutin, yaitu Lir-ilir yang dilaksanakan setiap bulan purnama, Macaning, Studi Klub Tari, Temu Mata, Performance Art Laboratory Project, undisclosed territory, dan lainnya. Padepokan ini terbuka bagi masyarakat umum untuk bisa menambah wawasan tentang karya seni yang meliputi seni pertunjukan, seni rupa, performing art, seni tradisional maupun kontemporer baik dari dalam hingga luar negeri (https://www.suara.com/news/2015/09/08/110946/kiprah-padepokan-lemah-putih-jagatradisi-agar-tak-punah)

Namun demikian, meningkatnya jumlah kunjungan wisatawan lokal, tidak diikuti dengan meningkatnya kunjungan wisatawan mancanegara. Kunjungan wisatawan mancanegara hanya berada di padepokan lemah putih sebelum era reformasi, sedangkan ketika era reformasi, kunjungan wisatawan mancanegara sudah jarang sebab sudah meningkatnya biro travel yang menawarkan kunjungan pariwisata ke wilayah lain yang memiliki nilai lebih dalam hal etnik, kreatifitas, dan inovasi. Oleh karena itu diperlukan penyuluhan dan pengarahan tentang pentingnya fasilitasi wisatawan mancanegara dalam bentuk bahasa Inggris lisan maupun tulisan, dilanjutkan dengan identifikasi ragam bahasa inggris yang diperlukan oleh masyarakat dan wisatawan mancanegara untuk menunjang kenyamanan baik dalam memberikan pelayanan bagi wisatawan mancanegara maupun ketika mereka berkunjung ke desa Plesungan, serta mengadopsi model layanan bahasa Inggris dari desa wisata yang 
sudah memberikan fasilitasi bahasa Inggris bagi. Dari penjelasan diatas pengusul hendak memfasilitasi desa Plesungan melalui kegiatan pengabdian dengan judul "ANALISIS KEBUTUHAN BAHASA INGGRIS UNTUK MEWUJUDKAN DESA WISATA PENDIDIKAN SENI DAN BUDAYA DI DESA PLESUNGAN" yang bertujuan untuk mengidentifikasi ragam bahasa Inggris yang diperlukan oleh masyarakat desa Plesungan untuk memfasilitasi wisatawan mancanegara yang berkunjang ke desa Plesungan dan mengidentifikasi ragam bahasa Inggris yang digunakan oleh wisatawan mancanegara ketika berkunjung ke desa wisata sebagai bahan untuk merancang bentuk fasilitasi masyarakat dalam bentuk bahasa Inggris yang mereka perlukan.

\section{METODE PELAKSANAAN}

Deskripsi hasil pengabdian dipaparkan sesuai dengan hasil dari solusi permasalahan yang telah dituliskan pada bab solusi dan target luaran.

\section{A. Hasil pengabdian ketika dilaksanakan penyuluhan, pengarahan, dan dialog dengan masyarakat, perangkat desa, dan tokoh masyarakat untuk bertukar ide dan gagasan untuk mewujudkan desa wisata yang ramah bagi wisatawan mancanegara dalam hal berbahasa Inggris.}

Pengabdi melaksanakan penyuluhan, pengarahan, dan berdialog dengan kepala desa dan pengurus serta pegawai badan usaha milik desa (BUMDES) desa Plesungan tentang konsep desa wisata, tujuan dibentuknya desa wisata, dan bentuk keterlibatan masyarakat dalam pembentukan desa wisata. Dikutip dari Soemarno (2010) bahwa Desa wisata merupakan suatu kawasan pedesaan yang menawarkan keseluruhan suasana yang mencerminkan keaslian pedesaan baik dari kehidupan sosial ekonomi, sosial budaya, adat istiadat, keseharian, memiliki arsitektur bangunan dan struktur tata ruang desa yang khas, atau kegiatan perekonomian yang unik dan menarik serta mempunyai potensi untuk dikembangkannya berbagai komponen kepariwisataan, misalnya atraksi, akomodasi, makanan-minuman, cindera-mata, dan kebutuhan wisata lainnya.

Selanjutnya pengabdi menyampaikan tentang tujuan dibentuk nya desa wisata, diantaranya (a) pengembangan wisata berbasis masyarakat seperti desa wisata secara makro bisa meningkatkan kesempatan kerja dari 11 juta menjadi 13 juta, sehingga 
ketimpangan ekonomi dapat teratasi karena masyarakat akan banyak memiliki kesempatan untuk bekerja di sektor pariwisata (Sastrayuda, 2010), (b) masyarakat desa menjadi lebih mandiri dalam memajukan daerahnya, (c) memberikan pelayanan optimal kepada wisatawan. (Suseno et al, 2015), (d) mengenali jenis wisata yang sesuai dan melengkapi gaya hidup yang disukai penduduk setempat, (e) memberdayakan masyarakat setempat agar bertanggung jawab terhadap perencanaan dan pengelolaan lingkungannya, (f) mengupayakan agar masyarakat setempat dapat berperan aktif dalam pembuatan keputusan tentang bentuk pariwisata yang memanfaatkan kawasan lingkungannya, dan agar mereka, mendapat jaminan memperoleh bagian pendapatan yang pantas dari kegiatan pariwisata, (g) mendorong kewirausahaan masyarakat setempat, dan (h) mengembangkan produk wisata desa.

Selanjutnya pengabdi menyampaikan tentang wujud partisipasi masyarakat untuk mengembangkan desa wisata (community based tourism), yaitu (a) gaya hidup dan kualitas hidup masyarakatnya berupa ekonomi, fisik dan sosial daerah pedesaan tersebut, misalnya ruang, warisan budaya, kegiatan pertanian, bentangan alam, jasa, pariwisata sejarah dan budaya, serta pengalaman yang unik dan eksotis khas daerah, dan (b) gaya hidup dan kualitas hidup masyarakatnya secara khusus berkaitan dengan perilaku, integritas, keramahan. Selanjutnya pengabdi menyampaikan tentang kebutuhan bahasa Inggris di desa wisata, yaitu (a) bahasa Inggris sebagai alat komunikasi antara pelaku usaha wisata dengan wisatawan secara lisan, dan (b) bahasa Inggris sebagai media untuk mempromosikan kekayaan desa baik dari segi ekonomi, sosial, seni budaya, dan alam melalui promosi fisik (leaflet, dsb) internet (media online \& media sosial).

B. Hasil pengabdian dengan mengidentifikasi ragam bahasa inggris yang diperlukan oleh masyarakat dan wisatawan mancanegara ketika mereka berkunjung ke desa Plesungan, dan Mengadopsi model layanan bahasa Inggris dari desa wisata yang sudah memberikan fasilitasi bahasa Inggris bagi wisatawan mancanegara.

Dari hasil studi pustaka tentang ragam bahasa Inggris di desa wisata dan analisa kebutuhan bahasa Inggris di desa Plesungan, maka ragam bahasa Inggris yang diperlukan dapat dipaparkan sebagai berikut:

1. Mengecek informasi dari beragam sumber (Checking Information from any resources) 
Mengecek informasi merupakan kegiatan yang dilaksanakan baik oleh wisatawan mancanegara maupun pelaku usaha wisata desa Plesungan. Wisatawan mancanegara mengecek informasi tentang desa plesungan melalui internet, leaflet, maupun media sosial sehingga diperlukan deskripsi profil yang bersifat lengkap, jelas, dan informative tentang desa Plesungan. Mereka juga mengecek informasi dari penjelasan tour guide apabila mereka menggunakan jasa tersebut, oleh karena itu tour guide perlu memahami profil desa secara komprehensif dan jelas. Pengecekan informasi juga bias dilakukan oleh wisatawan mancanegara dengan bertanya dengan customer service desa plesungan atau bumdes yang mengelola kepariwisataan desa, oleh karena itu diperlukan adanya customer service yang mampu berbahasa inggris secara aktif dan memahami profil desa dengan baik.

Pengecekan informasi oleh pelaku usaha wisata desa plesungan bisa dilaksanakan dengan mendata profil wisatawan mancanegara yang akan berkunjung ke desa plesungan. Pengecekan asal Negara, tujuan berkunjung, kemampuan berbahasa, minat jenis makanan, dan sebagainya maka akan memudahkan desa untuk memberikan bentuk pelayanan dan fasilitasi yang baik dan berstandar serta sesuai harapan pengunjung. Apabila wisatawan mancanegara tidak melakukan reservasi dan langsung menuju obyek wisata, maka fihak desa dapat memberikan form isian tentang hal tersebut diatas sehingga dapat memberikan pelayanan yang baik.

\section{Saling Tukar Informasi (Exchanging Personal Information)}

Aktifitas saling bertukar informasi antara wisatawan mancanegara (Wisman) dengan pelaku usaha wisata desa diperlukan dalam rangka mengetahui profil desa dan mengetahui informasi tentang pengunjung untuk memberikan pelayanan yang optimal. Informasi tentang Wisman diantaranya asal Negara, tujuan berkunjung, kemampuan berbahasa, minat jenis makanan, bentuk layanan penginapan, dan schedule berkunjung ke obyek wisata akan memudahkan pemberian pelayanan kepada wisman sebab apabila mereka tidak bisa berbahasa Inggris dan mereka hanya cakap berbahasa asal semisal bahasa jepang, maka fihak desa dapat memfasilitasi dengan menyediakan guide yang mampu berbahasa Jepang. Informasi yang dimaksuk bisa dalam bentuk lisan maupun tertulis. Informasi secara lisan tentang desa diperlukan oleh wisman untuk menentukan obyek wisata mana yang akan dikunjungi dan menjadwalkan kunjungan. Oleh karena itu setiap pelaku usaha wisata diharapkan menguasai bahasa inggris lisan untuk memberikan informasi tentang desa. 


\section{Menyapa (Greeting)}

Saling menyapa antara Wisman dan pelaku usahan wisata diperlukan untuk memberikan penghormatan yang baik dan pelayanan yang memuaskan meskipun dalam bentuk bahasa. Sapaan meskipun bersifat formalitas namun dapat menghidupkan suasana dan meningkatkan minat berkunjung ke desa. Sapaan berbahasa Inggris diantaranya saying hello, good morning, afternoon, evening, asking the trip to go to Plesungan, how many days they will visit, dan sebagainya.

4. Mendeskripsikan obyek wisata lokal (Describing local tourism destination)

Kecakapan dalam mendeskripsikan obyek wisata desa Plesungan secara lisan diperlukan oleh setiap pelaku usaha wisata untuk mengenalkan, menyampaikan profil obyek, dan mendeskripsikan kelebihan obyek sehingga Wisman memperoleh informasi yang komprehensif dan puas terhadap pelayanan. Deskripsi obyek secara lisan harus relevan dengan kondisi nyata obyek tersebut sehingga tidak mengecewakan. Bentuk ragam bahasa dalam hal mendeskripsikan obyek, diantaranya tentang what and where the tourism object is, how to get there, why we visit it, when we visit it, how we can go there, dan sebagainya.

Penjelasan tentang destinasi wisata desa diperlukan untuk memberikan wawasan dan pilihan obyek wisata serta memberikan informasi tentang schedule rencana kunjungan. Disamping itu juga menjelaskan tentang kelebihan obyek wisata tersebut tidak hanya bagi pengunjung, namun bagi desa. Bentuk bahasa Inggris yang bisa digunakan adalah the village has many tourism destinations, they are sendang plesungan, reog and dance performance, dan sebagainya.

5. Mengenalkan pertunjukan kepada Wisman (Introducing local performance)

Pertunjukan desa plesungan berupa tradisi sedekah bumi dengan mengarak dan membagikan 1000 tumpeng dari kantor desa Plesungan dan reog, serta padepokan lemah Putih yang memiliki kegiatan Lir-ilir yang dilaksanakan setiap bulan purnama, Macaning, Studi Klub Tari, Temu Mata, Performance Art Laboratory Project, undisclosed territory, dan beragam kegiatan lainnya dapat dikenalkan secara lisan dan tertulis kepada Wisman. Dikenalkan secara lisan dalam bentuk komunikasi lisan antara pelaku usaha wisata dengan Wisman dan dikenalkan secara tertulis dengan mempromosikan di website, media sosial, dan leaflet. 


\section{Mendeskripsikan profil desa (Describing the profile of village)}

Mendeskripsikan informasi desa secara lisan melalui pelaku usaha wisata diperlukan untuk mengenalkan dan mempromosikan profil desa sehingga wisman bisa tertarik terhadap desa tidak hanya dari aspek kepariwisataan, namun juga dari aspek yang lain semisal tentang sumber daya alam, sumber daya manusia, fasilitas, prestasi desa, dan sebagainya.

7. Mendeskripsikan rencana atau progress obyek wisata baru (Describing the plan for new destination)

Potensi kepariwisataan di desa Plesungan yang masih dalam tahap kajian atau dalam tahap pembangunan dapat pula disampaikan kepada wisatawan asing untuk memberikan penjelasan tentang rencana pembangunan obyek wisata tersebut dan menyampaikan kelebihan-kelebihan obyek tersebut, serta meminta masukan dari Wisman tentang hal apa saja untuk menunjang kepariwisataan sehingga dapat memberikan pelayanan yang memuaskan bagi Wisman.

8. Memberikan rekomendasi tentang destinasi wisata baik di desa Plesungan maupun di luar desa (Giving recommendations about good destinations inside and outside the village)

Rekomendasi kunjungan wisata diperlukan untuk disampaikan kepada wisman untuk memberikan alternatif dan rekomendasi lokasi wisata didesa maupun di luar desa berdasarkan ulasan dari wisatawan yang lain, hasil riset, dan fakta di lapangan sehingga Wisman dapat memutuskan lokasi wisata yang akan dikunjungi ketika berkunjung maupun di sama yang akan dating. Bentuk kebahasaan yang bisa digunakan adalah I recommend, I suggest, based on the review of some/ many visitors, in fact, in reality, this place has various advantages, dan sebagainya.

9. Membantu dan memberikan pelayanan kebahasanaan selama tinggal di homestay (Assisting and giving a language service during staying at home stay)

Pelayanan dalam bentuk bahasa Inggris disamping pelayanan dalam bentuk akomodasi selama wisman menginap di home stay merupakan hal yang perlu diperhatikan sebab pelayanan bahasa dapat menunjang kepuasan pengunjung selama menginap, semisal melibatkan pengunjung dalam memasak makanan tradisional khas desa yang tentu saja memerlukan tidak hanya kecakapan memasak namun juga kecakapan berbahasa, 
memberikan penjelasan singkat tentang bentuk fasilitas di homestay, dan berbahasa inggris ketika menemani wisman makan di homestay merupakan wujud layanan bahasa Inggris bagi wisman.

\section{Mengajak berinvestasi (investment for the village)}

Mewujudkan desa wisata yang berdaya saing dan mandiri memerlukan investasi dari dalam maupun luar. Mengajak wisatawan asing berinvestasi merupakan hal yang tidak mustahil mampu meningkatkan fasilitas penunjang kepariwisataan. Bentuk ragam bahasa yang diperlukan adalah memberikan form isian berisi informasi pribadi pengunjung dan menganalisa hasil isian dari segi minat investasi, mengajak berbincang secara langsung tentang minat berinvestasi, dan mempromosikan potensi keuntungan berinvestasi. Namun ajakan berinvestasi ini dilaksanakan apabila hasil isian menunjukkan bahwa wisman berminat berinvestasi. Apabila wisman hanya berminat berwisata saja, lebih baik tidak memberikan penawaran investasi.

\section{Mengidentifikasi karakteristik masyarakat desa Plesungan untuk memetakan wujud partisipasi mereka dalam memberikan layanan berbahasa Inggris bagi wisatawan mancanegara.}

Dari segi sumber daya manusia, jumlah penduduk desa plesungan adalah sejumlah 8684 jiwa terdiri dari 2717 KK, 4424 laki-laki, 4261 perempuan, 2589 usia 0-15 tahun, 5202 termasuk usia 15-65 tahun, dan 893 termasuk usia 65 keatas. Sedangkan mata pencaharian warga desa adalah Pegawai Negeri Sipil sejumlah 78 orang, TNI / Polri sejumlah 8 orang, Swasta sejumlah 230 orang, Wiraswasta / Pedagang sejumlah 3700 orang, Petani sejumlah 350 orang, Tukang sejumlah 270 orang, Buruh Tani sejumlah 28 orang, Pensiunan sejumlah 26 orang, Peternak sejumlah 40 orang, Jasa sejumlah 90 orang, Pengrajin sejumlah 20 orang, Pekerja Seni sejumlah 22 orang, lainnya sejumlah 355 orang, dan Tidak bekerja /pengangguran sejumlah 40 orang. Data tersebut menunjukkan bahwa $75 \%$ warga desa Plesungan termasuk dalam usia produktif (usia 15 hingga 65 tahun) dan mayoritas warga Plesungan yaitu 35\% bekerja disektor wiraswasta (pedagang) sehingga dapat disimpulkan bahwa $75 \%$ warga masyarakat yang termasuk golongan usia produktif diharapkan untuk dapat mengembangkan potensi kepariwisataan dan seni budaya lokal didesa secara optimal khususnya dalam hal penguasaan bahasa Inggris kepariwisataan dan 35\% warga tergolong wiraswasta (pedagang) berpotensi dapat berkontribusi mendukung kepariwisataan dan seni 
budaya melalui pembuatan, pemasaran, dan penjualan produk lokal desa untuk meningkatkan perekonomian dan daya saing.

\section{PENUTUP}

Kesimpulan dari kegiatan ini adalah

1. Perguruan tinggi sebagai tangan panjang pemerintah dalam mencerdaskan kehidupan bangsa berperan memfasilitasi kegiatan tridharma dosen, diantaranya dengan pengabdian kepada masyarakat sehingga peran intelektual dosen memberikan kontribusi positif dalam pemberian masukan secara ilmiah yang bermanfaat untuk membuka fikiran dan wawasan masyarakat akan pentingnya keterlibatan mereka secara fisik, tenaga, fikiran, motivasi untuk perubahan dan peningkatan desa wisata menjadi lebih produktif, mandiri, dan berdaya saing. Pengabdian ini mensupport masyarakat terutama unsur pelaku usaha wisata desa dalam rangka pembinaan kebahasaan untuk memberikan pelayanan yang standar demi kenyamanan kunjungan wisatawan mancanegara.

2. Penguasaan bahasa inggris dasar yang memadai oleh para pelaku usaha wisata desa Plesungan merupakan embrio yang baik dan layak dalam rangka pengembangan layanan desa yang ramah terhadap wisatawan asing. Bahasa inggris dasar dapat ditularkan dan dikembangkan seiring dengan bertambahnya jumlah wisman dan frekuensi penggunaan bahasa. Perkembangan teknologi yang memfasilitasi penguasaan bahasa memungkinkan perkembangan penguasaan bahasa Inggris secara berkelanjutan dengan memanfaatkan media atau aplikasi pendukung penguasaan bahasa Inggris kepariwisataan. Selain pembinaan dan penyuluhan bahasa inggris kepariwisataan, peranan teknologi informasi sebagai wahana belajar mandiri berperan positif dalam mengembangkan kecakapan berbahasa masyarakat.

3. Pemanfaatan sumber daya alam desa merupakan diantara kunci mewujudkan dan menciptakan produk penciri desa oleh karena itu penyuluhan ini berkontribusi pula dalam membuka wawasan masyarakat tentang pentingnya pengolahan dan pemanfaatn SDA yang berpotensi meningkatkan ekonomi warga dan melestarikan produk lokal berstandar nasional yang merupakan penciri desa wisata Plesungan. 


\section{DAFTAR PUSTAKA}

Arief Budiman. 2018. Ogoh-Ogoh Hiasi Sedekah Bumi Desa Plesungan diakses dari https://radarsolo.jawapos.com/read/2018/04/19/66328/ogoh-ogoh-hiasi-sedekah-bumi-

desa-plesungan pada hari Rabu 06 November 2019 pukul 21.44 WIB di Karanganyar.

Sastrayuda, Gumelar. 2010. "Konsep Pengembangan Kawasan Ekowisata”. Yogyakarta

Siswanto. 2015. Kiprah Padepokan Lemah Putih Jaga Tradisi Agar Tak Punah diakses dari https://www.suara.com/news/2015/09/08/110946/kiprah-padepokan-lemah-putih-jagatradisi-agar-tak-punah pada hari Rabu 06 November 2019 pukul 21.44 WIB di Karanganyar.

Soemarno. 2010. Desa Wisata. (http://marno.lecture.ub.ac.id/files/2012/01/Desa-wisata.doc. pada hari Rabu 06 November 2019 pukul 21.44 WIB di Karanganyar.

Susena, Dewi Kartika Sari,et al.2015. Eksplorasi Potensi Ekowisata di Kawasan Api Tak Kunjung Padam Kabupaten Pamekasan. J-PAL, Vol. 6, No. 1, 2015 ISSN: 2087-3522 E-ISSN: 2338-1671 